CER-ETH - Center of Economic Research at ETH Zurich

Combining Energy Networks

J. Abrell and $\mathrm{H}$. Weigt

Working Paper 16/238

March 2016

Economics Working Paper Series

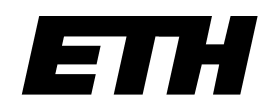

Eidgenössische Technische Hochschule Zürich Swiss Federal Institute of Technology Zurich 


\title{
Combining Energy Networks
}

\author{
Jan Abrell ${ }^{1}$ and Hannes Weigt ${ }^{2}$
}

\begin{abstract}
$\underline{\text { Abstract: }}$
Electricity markets depend on upstream energy markets to supply the fuels needed for generation. Since these markets rely on networks, congestion in one can quickly produce changes in another. In this paper we develop a combined partial equilibrium market model which includes the interactions of natural gas and electricity networks. We apply the model to a stylized representation of Europe's electricity and natural gas markets to illustrate the upstream and downstream feedback effects which are not obvious on first sight. We find that both congestion and loop-flow effects in electricity markets impact prices and quantities in markets located far from the initial cause of the market changes.
\end{abstract}

Keywords: Electricity network, Natural gas network, Europe, MCP

JEL-Codes: L94, L95, C63

\footnotetext{
${ }^{1}$ Swiss Federal Institute of Technology Zürich, Center for Energy Policy and Economics at ETH Zurich, Zürichbergstrasse 18, CH-8032 Zürich, Switzerland. jabrell@ethz.ch

${ }^{2}$ Forschungsstelle Nachaltige Energie- und Wasserversorgung, Wirtschaftswissenschaftliche Fakultät der Universität Basel, Peter Merian-Weg 6, Ch-4002 Basel, Switzerland. hannes.weigt@unibas.ch
} 


\section{Introduction}

In the coming decades, energy markets around the world face a multitude of challenges, such as ongoing restructuring process, emission restrictions, support for renewables, reliability, smart grid technology, and security of supply. Electricity markets are the linkage between different fuel markets due to fuel substitution. Consequently, decisions about future market developments, such as the projected ENTSO-E Ten-Year Network Development Plan, or increased imposition of carbon regulations, directly impact the upstream fuel markets, while decisions such as the projected increase in LNG import capacities in Europe directly impact the downstream electricity market since they influence the availability of fuels and change the price levels. Investment and market decisions are further complicated because most fuel markets rely on network infrastructure, e.g. pipeline, sea routes, and railways, for transmission and local distribution. Similarly, electricity markets must account for the physics of power-flows. The different networks are characterized by a substitution relationship, e.g. either the fuel is imported to generate electricity locally, or the electricity is imported. However, this substitution is bounded by the capacity of the transmission grid, meaning that congestion effects typical for grid-bounded transportation must be considered when analyzing the interaction of energy markets and the energy system as a whole. The objective of this paper is to develop a modeling framework that accounts for the interaction of fuel and electricity markets while simultaneously respecting their network character.

The connection of energy markets via electricity generation which relies on fossil fuels as the production input and the grid-bounded transportation of most fuels have given rise to two numerical modeling approaches. Energy system models tend to highlight the price interaction between single energy markets, including a detailed description of the value chains such as extraction, transmission, and final demands, but they also tend to simplify transmission modeling by abstracting from networks like natural gas pipelines or electricity grids. In a partial equilibrium setting ${ }^{3}$ the models are formulated in an optimization framework, e.g. MARKAL (Loulou et al. 2004), POLES (Kouvaritakis et al., 2000), MESSAGE (Grübler and Messner 1998), or in an equilibrium format, e.g. LIBEMOD (Aune et al. 2001). Macroeconomic-oriented models are represented in a general equilibrium framework either in a computable general equilibrium format, e.g. MIT-EPPA (Paltsev et al. 2005) and GEM-E3 (Capros et al. 1997), or as intertemporal welfare-maximizing Ramsey-type models, e.g. REMIND (Bauer et al. 2008). Technically-oriented simulation and optimization models look at material flows, optimal fuel usage, or generation mix, e.g. PERSEUS-EEM (Möst and Perlwitz 2009), which incorporates a natural gas pipeline model in a cost-minimizing inter-regional long-term model. They approximate electricity transport by net-transfer capacities which do not explicitly model loopflows unlike the approach discussed in our paper.

\footnotetext{
${ }^{3}$ We use the term "partial equilibrium" models in contrast to "general equilibrium" models which deal with the endogenous determination of final consumers' income and maintain the circular flow of commodities and monetary values.
} 
On the other hand, single energy models tend to emphasize on the detailed representations of the technological details of grid-bounded transmission in a specific market with particular focus on the role of imperfect competition. Mathiessen et al. (1987) show that the European natural gas market is best described by a Cournot duopoly. Gabriel et al. (2005) and Egging et al. (2009) present a NashCournot framework of the US and European natural gas markets, including pipeline and Liquefied Natural Gas (LNG) transportation. EWI Cologne has produced a series of linear optimization models of which the TIGER model provides the most detailed dispatch model for Europe and is best suited for identifying congestion (Perner and Seeliger 2004; Lochner and Bothe 2007). Holz (2009) discusses these different model families in detail. Network-oriented electricity market models include powerflows along different lines. In contrast to natural gas pipelines, the power-flow in an electricity network is physically determined by the injections and withdrawals at nodes. Smeers (1997) and Ventosa et al. (2005) provide an overview of numerical modeling approaches. As natural gas models, network-oriented electricity models examine the effects of imperfect competition (e.g. Hobbs 2001; Neuhoff et al. 2005). Network models applying the DC load-flow approach are commonly used for economic market analyses (e.g. Stigler and Todem 2005; Green, 2007; Leuthold et al. 2008).

To our knowledge, the interconnection of energy transmission networks has not received attention in the energy-economic literature, although the engineering literature does discuss the challenge of combining grid-bounded electricity and natural gas transportation. An et al. (2003) present a simplified model combining networks at a single node. Their combined natural gas and electric optimal power flow problem (GEOPF) considers natural gas transportation at a disaggregated distribution stage, i.e. the direction and flow of natural gas in the network are controlled via compressors. Thus, the GEOPF results in an integer problem regarding the natural gas flows. ${ }^{4}$ The approach has been extended by e.g. Unisihuay et al. (2007) for multiple interconnection points. Arnold et al. (2008) present a decomposition approach for the GEOPF in order to allow larger dimension applications. While the GEOPF approach represents technological details in great detail, it is limited from an economic point of view since the usage of integer variables leads to problems representing price variables (O’Neil et al. 2005).

In this paper, we present a general framework to combine energy markets, including detailed network characteristics using the mixed complementarity problem format. The model is written in the partial equilibrium framework to allow easy incorporation of further market elements. Concentrating on the natural gas transmission stage, i.e. assuming directed pipeline flows but avoiding integer modeling problems, our approach provides a more detailed analysis of energy systems on a large scale. Similar, focusing on electricity transmission, we derive a flow-based market representation applying the DC load-flow approach. The coupling of both markets is conducted via the demand market clearing price in the natural gas market and the electricity generators' cost function considering the endogenous gas price. We test the approach on a stylized model of the European energy market with two scenarios: 1.

\footnotetext{
${ }^{4}$ Put differently, at the distribution stage pipeline flows are undirected. Thus, the decision to use compressors results in an integer decision over the direction of natural gas flowing in the pipeline.
} 
the reduction of natural gas imports from Russia, and 2. the imposition of a carbon emission constraint on the European electricity sectors. The interaction demonstrates the importance of a combined market assessment.

The remainder of this paper is structured as follows. Section 2 describes the modeling framework. The single market models are presented followed by a description of the combined model. In Section 3, we parameterize the modeling framework to a European Union test case, describe the scenarios and present the results. Section 4 summarizes our work and discusses our conclusions.

\section{Model Description}

Following we formulate the market representations for electricity, natural gas and the combined setting. The models are defined as a Mixed Complementarity Problem (MCP) (e.g. Rutherford 1995):

$$
\begin{aligned}
& \text { given } \mathrm{f}: \mathfrak{R}^{\mathrm{n}} \rightarrow \mathfrak{R}^{\mathrm{n}} \\
& \text { find } \mathrm{r} \in \mathfrak{R}^{\mathrm{n}} \\
& \text { s.t. } \quad \mathrm{r} \geq 0 \quad \mathrm{f}(\mathrm{r}) \geq 0 \quad \mathrm{r}^{\mathrm{T}} \mathrm{f}(\mathrm{r})=0
\end{aligned}
$$

We formulate the model in a complementarity format for two reasons. First, unlike optimization problems, the complementarity formulation explicitly represents prices and quantities, making it possible to simultaneously account price and quantify restrictions. Second, the complementarity formulation states an equilibrium problem, which makes it easy to adopt different equilibrium concepts. In the article we impose the perfect competition equilibrium concept, i.e. all agents take prices as given. We chose this approach mainly due its simplicity allowing us to concentrate on the combination of the presented network models.

The considered markets differ in their network representation, but have similarities in the definitions of producer and consumer behaviors. We assume that producers maximize their profits given technical constraints, whereas we define consumer behavior via a demand function. Each producer is endowed with production capacity with a specific unit cost. We assume one system operator manages the network and clears production and demand. Despite being designed as a spot market structure, the formulation represents medium- to long-term relationships between the natural gas and electricity markets. In the short run (e.g. the spot market price for day-ahead natural gas and electricity), both markets do not interact since the connection via fuel prices requires some adjustment time to produce feedback effects (e.g. the shift from gas-fired generation to other fuels).

Similar formulations of our single models can be found in the literature. For example, our natural gas model framework resembles e.g. Egging et al. (2008) and Holz (2009). However, these authors apply a Nash-Cournot equilibrium concept. Our basic electricity market framework is similar to Hobbs (2001), who also applies a Nash-Cournot equilibrium concept. Section 2.3 discusses the interaction and combination of the separated market frameworks.

The MCP formulation of our models is derived by setting up the optimization problem of each agent in the respective markets. We then derive the first order complementarity conditions and use them in 
the MCP formulation. Furthermore, we add so-called market clearing equations which state that supply must be greater or equal to the demand in the market. These equations are complementary to the price in the respective markets. In Fig. 1, the ovals are the market participants and the rectangles are the different markets in which the participants interact. The left side represents the natural gas market with the three sub markets. The right side represents the electricity market with the supply and demand sides connected by commodity transactions and the system operator managing physical flows. The natural gas market is connected to the electricity market via the fuel market linking natural gas demand and electricity generators. Table 1 provides the notation of the model.

Table 1: Notation

\begin{tabular}{|c|c|c|c|}
\hline \multicolumn{2}{|r|}{ Indexes and Set } & \multicolumn{2}{|r|}{ Variables } \\
\hline$e \in E$ & Node in the electricity network & $D E M$ & Demand \\
\hline$f \in F$ & Fuels & $F$ & Flow \\
\hline$g, h \in G$ & Nodes in natural gas network & $P$ & Price \\
\hline$\tilde{g} \in G$ & Origin node of natural gas & $P C$ & Scarcity prices of capacity \\
\hline$i \in I$ & Plant types & $P D$ & Demand price \\
\hline gas $C I$ & Natural gas plants & $P E$ & Carbon emission price \\
\hline gas $C F$ & Natural gas fuel & $P F$ & Fuel price (endogenous) \\
\hline$l \in L$ & Lines in the electricity network & PHUB & Marginal system price in the electricity market \\
\hline \multirow[t]{7}{*}{$G E$} & Mapping between $G$ and $E$ & $P N$ & Nodal price \\
\hline & & $P S$ & Supply price \\
\hline & & $P T$ & Transport service price \\
\hline & & $T$ & Transporter and traded volume \\
\hline & & $X$ & Natural gas extraction \\
\hline & & $Y$ & Power injected/withdrawn into electricity grid \\
\hline & Parameters & & Superscripts \\
\hline$\alpha$ & LNG liquefaction loss & $+/-$ & Positive or negative direction \\
\hline$\beta$ & LNG regasification loss & buy & Bought quantity \\
\hline$\eta$ & Plant efficiency & emi & Emissions \\
\hline$\theta$ & Carbon content of fuels & el & Electricity \\
\hline$a$ & Demand function intercept & gas & Natural gas \\
\hline$b$ & Demand function slope & line & Lines in electricity network \\
\hline$c$ & Marginal cost & $\operatorname{liq}$ & Liquefaction \\
\hline cap & Capacity & $L N G$ & Liquefied natural gas \\
\hline$E$ & Emission level & $\max$ & Upper limit \\
\hline$p f$ & Fuel price (exogenous) & pipe & Pipeline \\
\hline$P T D F$ & Power Transmission Distribution Factor & reg & Regasification \\
\hline
\end{tabular}

\subsection{The natural gas market}

In the natural gas model, gas is transported using pipelines or LNG tankers. Independent of the network chosen, the operator of that network has full control over the gas in the network.

We denote nodes in the natural gas network by $g$ and $h \in G$. Nodes in the natural gas network are connected via arcs called pipelines denoted as ordered pairs $(g, h) \in G x G$. Thus, the natural gas flows along directed arcs. Each pipeline is characterized by its capacity $c a p_{g h}{ }^{p i p e}$ which implicitly defines the set of pipelines if the capacity is strictly greater than zero. Natural gas transport via LNG is not restricted by arc capacities, but by the technical characteristics of the connected nodes. An LNG source node must have a positive liquefaction capacity ( cap $_{g}^{l i q}$ ). Furthermore, an LNG destination 
node is characterized by a positive regasification capacity $\left(\mathrm{cap}_{g}{ }^{\text {reg }}\right)$. Therefore, these parameters implicitly define the (directed) arcs of the LNG network.

There are five market participants: natural gas producers, traders, ${ }^{5}$ pipeline operators, LNG operators, and final consumers. Producers extract the natural gas and sell it either to the traders or to the LNG operator. The LNG operator buys from producers at some node (with liquefaction capacity), transports the gas to another node (with regasification capacity), and sells it to traders. Traders can buy natural gas from producers or LNG operators, buy the service to transport the gas from the pipeline operator, and sell the gas to the final consumers. The pipeline owner operates the network and rents out capacity to the traders. Consequently, final consumers are served by traders only.

Fig. 1 Model overview

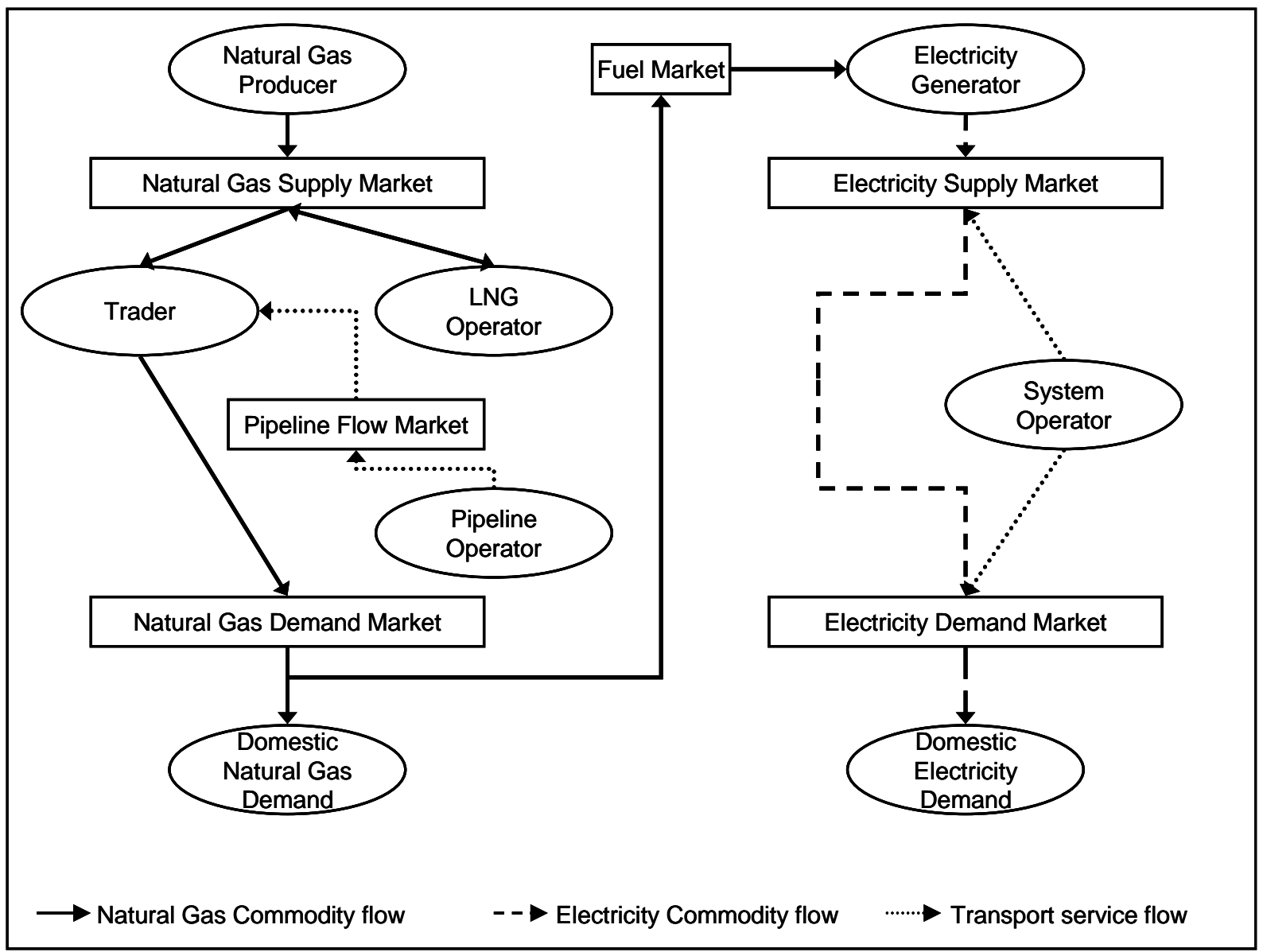

Source: Own illustration.

The natural gas producer located at node $g$ is characterized by constant extraction costs $c_{g}{ }^{g a s}$ and its extraction capacity $\operatorname{cap}_{g}{ }^{g a s}$. Assuming perfect competition, each producer maximizes its profit under the extraction capacity restriction, choosing the extraction quantity $X_{g}^{g a s}$ given the natural gas supply price $P S_{g}{ }^{g a s}$ :

$$
\max _{X_{g}^{g a s} \geq 0}\left(P S_{g}^{\text {gas }}-c_{g}^{g a s}\right) X_{g}^{\text {gas }}
$$




$$
\text { s.t. } \operatorname{cap}_{g}^{\text {gas }} \geq X_{g}^{\text {gas }} \quad \perp \quad P C_{g}^{\text {gas }} \geq 0 \quad \forall \mathrm{g} \in \mathrm{G}
$$

$P C_{g}{ }^{g a s}$ is the scarcity price of the extraction capacity at node $g$. The first order conditions of natural gas producers become: 6

$$
c_{g}^{g a s}+P C_{g}^{g a s} \geq P S_{g}^{g a s} \quad \perp \quad X_{g}^{g a s} \geq 0 \quad \forall g \in G
$$

together with equation (2). The left side of equation (3) shows the costs of extracting one unit of natural gas which are given as the sum of the marginal extraction cost and scarcity price of the available extraction capacity. The right side gives the supply price as the profit of extracting one unit. Thus, the complementarity condition (3) can be interpreted as a zero-profit condition: Either the unit costs of extraction are equal to the unit profit and production is (weakly) positive, or the costs exceed the profit and the economic activity natural gas extraction becomes zero.

The LNG network operator buys natural gas at node $g$ from the producers at the supply price and sells it at node $h$ also at the supply price to traders. LNG transport on a specific route from $g$ to $h$ incurs constant units cost $c_{g h}{ }^{L N G}$. Furthermore, liquefaction and regasification require energy in the form of natural gas. Therefore, after the liquefaction process only fraction $\alpha$ remains of the natural gas purchased. After the liquefaction process, the transported amount is further reduced by fraction $\beta$ of the transport volume during the regasification process. The LNG operator maximizes its profit under the regasification and liquefaction constraint choosing the transported volume $T_{g h}{ }^{L N G}$ (i.e. the volume net of liquefaction losses but gross of regasification losses) given prices:

$$
\begin{array}{cccc}
\max _{T_{g h}^{L N G} \geq 0} \sum_{g, h}\left(\beta P S_{h}^{\text {gas }}-\frac{P S_{g}^{\text {gas }}}{\alpha}-c_{g h}^{L N G}\right) T_{g h}^{L N G} & \\
\text { s.t. } \operatorname{cap}_{g}^{r e g} \geq \sum_{h} \beta T_{h g}^{L N G} \quad \perp \quad & P C_{g}^{r e g} \geq 0 & \forall \mathrm{g} \in \mathrm{G} \\
\operatorname{cap}_{g}^{l i q} \geq \sum_{h} T_{g h}^{L N G} \quad \perp C_{g}^{l i q} \geq 0 & \forall \mathrm{g} \in \mathrm{G}
\end{array}
$$

$P C_{g}^{l i q}$ and $P C_{g}{ }^{r e g}$ are the scarcity prices of liquefaction and regasification capacity, respectively. The corresponding first order conditions for the transported LNG volume become:

$$
c_{g h}^{L N G}+\frac{P S_{g}^{g a s}}{\alpha}+P C_{g}^{l i q}+\beta P C_{h}^{r e g} \geq \beta P S_{h}^{g a s} \quad \perp \quad T_{g h}^{L N G} \geq 0 \quad \forall \mathrm{g}, \mathrm{h} \in \mathrm{G}
$$

together with condition (4) and (5). Again, condition (6) can be interpreted in terms of zero-profits, noting the unit cost as the sum of transport, purchase, and capacity cost on the right side and the unit profit on the left side.

\footnotetext{
${ }^{5}$ The introduction of a trader is based on Egging et al. (2008)

${ }^{6}$ The perpendicular sign $\perp$ denotes complementarity. In the example of equation (1) the extended formulation would be $c_{g}^{g a s}+P C_{g}^{g a s} \geq P S_{g}^{\text {gas }} ; X_{g}^{\text {gas }} \geq 0 ; \quad\left(c_{g}^{\text {gas }}+P C_{g}^{\text {gas }}-P S_{g}^{\text {gas }}\right) X_{g}^{\text {gas }}=0$. To avoid repeated statements of equations, we use the perpendicular sign in the optimization problem to associate dual multipliers with constraints and to represent the respective first order condition, i.e. we always solve optimization problems constraint by equations and never solve them under complementarity conditions.
} 
The trader buys natural gas at node $\tilde{g}\left(T_{\tilde{g}}^{b u y}\right)$ and sells it at node $h\left(T_{\tilde{g} h}^{g a s}\right){ }^{7}$ In order to transport the natural gas via pipelines, the trader needs to rent the capacity for the induced flow $F_{g}^{g a s}$ originated at node $\tilde{g}$ and routed along the pipeline from node $g$ to node $h$. This service is priced with the pipeline transport price $P T_{g h}{ }^{p i p e}$. Therefore, the trader maximizes its profit by choosing the purchased and sold amount of natural gas and the flow along the pipelines under the flow conservation constraint for each node. As we assume perfect competition, the trader takes the supply, demand, and transport service prices as given:

$$
\begin{aligned}
& \max _{T_{\tilde{g}}^{b u y}, T_{g h}^{g a s}, F_{\tilde{g} g h}^{g a s} \geq 0} \sum_{\tilde{g}}\left[\sum_{h} P D_{h}^{g a s} T_{\tilde{g} h}^{g a s}-P S_{\tilde{g}}^{g a s} T_{\tilde{g}}^{b u y}\right]-\sum_{\tilde{g} g h} P T_{g h}^{p i p e} F_{\tilde{g} g h}^{g a s} \\
& \text { s.t. } \quad \sum_{g} F_{\tilde{g} g h}^{g a s}+\left(T_{\tilde{g}}^{b u y}\right)_{i f \tilde{g}=h}=\sum_{g} F_{\tilde{g} h g}^{g a s}+T_{\tilde{g} h}^{g a s} \quad \perp \quad P N_{\tilde{g} h}^{g a s} \text { free } \quad \forall \tilde{\mathrm{g}}, \mathrm{h} \in \mathrm{G}
\end{aligned}
$$

$P N_{\tilde{g} h}^{g a s}$ is the nodal price at node $h$ of the gas purchased at node $\tilde{g}$. The corresponding first-order conditions for the purchased and sold amounts and the pipeline flow are:

$$
\begin{array}{rlll}
P N_{\tilde{g} h}^{\text {gas }} \geq P D_{h}^{g a s} & \perp & T_{\tilde{g} h}^{g a s} \geq 0 & \forall \tilde{\mathrm{g}}, \mathrm{h} \in \mathrm{G} \\
P S_{\tilde{g}}^{\text {gas }} \geq P N_{\tilde{g} \tilde{g}}^{g a s} & \perp & T_{\tilde{g}}^{b u y} \geq 0 & \forall \tilde{\mathrm{g}} \in \mathrm{G} \\
P T_{g h}^{\text {pipe }}+P N_{\tilde{g} g}^{\text {gas }} \geq P N_{\tilde{g} h}^{g a s} & \perp & F_{\tilde{g} g h}^{g a s} \geq 0 & \forall \tilde{\mathrm{g}}, \mathrm{g}, \mathrm{h} \in \mathrm{G}
\end{array}
$$

together with equation (7). Condition (8) states that the nodal price at node $h$ has to equal the demand price $P D_{h}{ }^{g a s}$ in order to induce shipment of the natural gas originating at node $\tilde{g}$ satisfying demand at that node. Condition (9) states that the nodal price at node $\tilde{g}$ has to equal the supply price causing purchases of the trader at that node. Condition (10) equates the unit cost of the flow of the gas bought at $\tilde{g}$ shipped along the pipeline $(g, h)$ to the unit profit, implying positive flow at that pipeline.

The pipeline operator maximizes its revenues under the pipeline capacity constraints by choosing the total flow of natural gas along the pipeline connecting $g$ and $h\left(F_{g h}{ }^{p i p e}\right)$ given prices:

$$
\begin{gathered}
\max _{F_{g h}^{g a s} \geq 0} \sum_{g, h}\left(P T_{g h}^{p i p e}-c_{g h}^{p i p e}\right) F_{g h}^{p i p e} \\
\text { s.t. } \quad c a p_{g h}^{p i p e} \geq F_{g h}^{p i p e} \quad \perp \quad P C_{g h}^{p i p e} \geq 0 \quad \forall \mathrm{g}, \mathrm{h} \in \mathrm{G}
\end{gathered}
$$

$P C_{g h}{ }^{p i p e}$ is the scarcity price of pipeline capacity. The first-order condition for the optimal flow along the pipelines results is:

$$
c_{g h}^{p i p e}+P C_{g h}^{p i p e} \geq P T_{g h}^{p i p e} \quad \perp \quad F_{g h}^{p i p e} \geq 0 \quad \forall \mathrm{g}, \mathrm{h} \in \mathrm{G}
$$

together with equation (11). Condition (12) shows that the transport service price must equal the sum of the marginal cost of pipeline transport and the scarcity price of pipeline capacity in order to induce a positive flow along a pipeline.

Final consumers are represented by a linear demand function:

\footnotetext{
$7 \tilde{g}$ denotes the origin of the natural gas.
} 


$$
D E M_{g}^{g a s}=a_{g}^{g a s}+b_{g}^{g a s} P D_{g}^{g a s} \quad \perp \quad D E M_{g}^{\text {gas }} \geq 0 \quad \forall \mathrm{g} \in \mathrm{G}
$$

where $D E M_{g}{ }^{g a s}$ and $P D_{g}{ }^{g a s}$ are natural gas demand and price at node $g$ and $a_{g}{ }^{g a s}\left(b^{g}{ }^{g a s}\right)$ are strictly positive (non-positive) constants. We decide to represent demand by a linear function because it keeps the model in a linear framework which facilitates solving. Furthermore, the parameters of linear functions can be easily determined, given a point estimate of the demand elasticity and the corresponding reference point. In contrast, determining the parameters of a non-linear demand function requires at least an econometric estimate of an arc elasticity or separate estimation of the parameters.

Market prices are determined by market clearing conditions. These conditions state that supply in a market has to be larger or equal to the demand in that market. Complementarity states that if supply exceeds demand the commodity is non-scarce and the commodity price becomes zero. If, however, the market clears, i.e. supply equals demand, the price becomes (weakly) positive as the commodity is scarce. In the natural gas model three kinds of markets exist (see Fig. 1): Supply, demand, and transport service. In supply markets the supply is given as the sum of production and the amount shipped via LNG to that node. Demand consists of purchases by the trader and LNG shipped away from this node (including liquefaction losses):

$$
X_{g}^{g a s}+\sum_{h} \beta T_{h g}^{L N G} \geq T_{g}^{b u y}+\sum_{h} \frac{T_{g h}^{L N G}}{\alpha} \quad \perp \quad P S_{g}^{g a s} \geq 0 \quad \forall \mathrm{g} \in \mathrm{G}
$$

In the demand market supply is given as the amount shipped by the trader to that node and the demand is determined by the demand function:

$$
\sum_{h} T_{h g}^{\text {gas }} \geq D E M_{g}^{\text {gas }} \quad \perp \quad P D_{g}^{\text {gas }} \geq 0 \quad \forall \mathrm{g} \in \mathrm{G}
$$

The market clearing condition for pipeline flows determines the transport price along a given pipeline:

$$
F_{g h}^{\text {pipe }} \geq \sum_{\tilde{g}} F_{\tilde{g} g h}^{g a s} \quad \perp \quad P T_{g h}^{p i p e} \geq 0 \quad \forall \mathrm{g}, \mathrm{h} \in \mathrm{G}
$$

The full natural gas model consists of conditions (2) to (16).

\subsection{The electricity market}

Contrary to flows in the natural gas network which are under the control of the network operator, power flows in an electricity network are determined by Kirchhoff's laws. Thus, injections and withdrawals at nodes impact the whole power flow pattern in the system and lead to the problem of loop-flows. ${ }^{8}$ Consequently, the system operator's choice variables are the amount of power injected or withdrawn at different nodes, while the flows are solely determined by physical laws.

\footnotetext{
${ }^{8}$ For example, transporting electricity from the north of Germany to the south of Germany also leads to cross- border flows through the Benelux and France.
} 
We denote nodes in the electricity network by e $\epsilon E$. The nodes are partly connected by arcs called lines $l \in L \subseteq E x E$. In contrast to the natural gas networks, the lines are not ordered pairs of nodes because electricity can flow in both directions. Each line is characterized by its capacity cap line

The three market participants are electricity producers, the electricity system operator, and the final consumers. Electricity producers generate electricity and sell it to the system operator, who in turn sells the electricity to final consumers. The right of Fig. 1 illustrates the electricity market model.

The relevant nodal electricity price at node $e$ is divided into a marginal energy price defined via the market clearing of the whole system $(P H U B)$ and the transmission fee due to network congestion $\left(P T_{e}\right) .{ }^{9}$ These transactions are mere financial constructs capturing the resulting price divergences due to physical constraints. We derive the price at a node by summing those two components. Since $P T_{e}$ can be positive or negative, the locational price can diverge in both directions from the hub price.

Electricity producers at node $e$ are characterized by the available generation capacities of plant type $i$ $C I\left(\right.$ cap $\left._{i e}{ }^{e l}\right)$. The generation costs depend on the exogenously given price of fuel $p f_{f e}$ with $f \in F$ at node $e$ and the efficiency level $\eta_{f i e}$ depending on the plant and fuel type. ${ }^{10}$ In order to derive carbon emissions, each fuel is characterized by its physical carbon content $\theta_{\mathrm{f}}$. Assuming perfect competition, each generator maximizes its profit under the capacity restriction, choosing the generation quantity $X_{i e}^{e l}$ given the electricity price $P_{e}^{e l}$ consisting of $P H U B$ and $P T_{e}$ as well as the emission price $P E_{e}$ :

$$
\begin{array}{ll}
\max _{X_{e}^{e l \geq 0}} & \sum_{i}\left[\left(P T_{e}^{e l}+P H U B\right)-\sum_{f: \eta_{f i e}>0} \frac{p f_{f e}+\theta_{f} P E_{e}}{\eta_{f i e}}\right] X_{i e}^{e l} \\
\text { s.t. } & \operatorname{cap}_{i e}^{e l} \geq X_{i e}^{e l} \perp P C_{i e}^{e l} \geq 0 \quad \forall \mathrm{i} \in \mathrm{I}, \mathrm{e} \in \mathrm{E}
\end{array}
$$

$P C_{i e} e^{e l}$ is the scarcity price of the generation capacity of plant type $i$ at node $e$. Accordingly, the firstorder condition for each plant becomes:

$$
\frac{p f_{f e}+\theta_{f} P_{e}^{e m i}}{\eta_{f i e}}+P C_{e}^{e l} \geq P T_{e}^{e l}+P H U B \quad \perp \quad X_{i e}^{e l} \geq 0 \quad \forall \mathrm{i} \in \mathrm{I}, \mathrm{e} \in \mathrm{E}
$$

together with equation (17). Due to Kirchoff's laws, the electricity system operator does not trade on specific node pair combinations as in the natural gas setting, or even specific lines. The power flow pattern is determined once the injections/withdrawals are set. To derive a mathematical formulation of this problem, we include a hub node which routes network transactions. The system operator transfers all generated energy from the nodes $e$ to the hub node and in turn provides all demanded energy at the nodes $e$ via deliveries from the hub node. Thus, the system operator's choice variable is the amount of electricity transported to or from the hub to a node $\left(Y_{e}\right)$ which can be positive or negative depending of the definition of the energy balance (equation 23). Stated differently, the system operator decides the amount of electricity withdrawn or injected at node $e$. The price of transmitting power is denoted as

\footnotetext{
${ }^{9}$ The concept of introducing a hub price is based on Hobbs (2001).

${ }^{10}$ For the sake of simplicity, we assume that each plant type produces with only one fuel, i.e. for each (i,e) $\eta_{f i e}$ is strictly positive for exactly one fuel $f$. Therefore, the efficiency parameter also serves to establish a mapping between the generation technology set $I$ and the set of fuels $F$. Relaxing this assumption requires extending the range of the generation variable, i.e. introducing $X_{f i e} e^{e l}$ as the amount generated by plant $i$ at node $e$ using fuel $f$.
} 
$P T_{e}$ and the system operator maximizes its profits from transactions to and from the hub. The operator must ensure that the chosen injections and withdrawals at each node do not violate the existing line capacities $\operatorname{cap}_{l}^{\text {line }}$. In order to derive the power flow pattern we use power transmission distribution factors $\left(P T D F_{l e}\right)$ which state the share of a flow on line $l$ resulting from injections/withdrawals at node $e$. Taking prices as given, the system operator's problem becomes:

$$
\begin{array}{ccc}
\max _{Y_{e}} \sum_{e} P T_{e}^{e l} Y_{e} & \\
\text { s.t. } & \sum_{e} P T D F_{l e} Y_{e} \leq c a p_{l}^{\text {line }} \perp P C_{l}^{+} & \forall l \in L \\
& -\sum_{e} P T D F_{l e} Y_{e} \geq-\operatorname{cap}_{l}^{\text {line }} \perp P C_{l}^{-} & \forall l \in L
\end{array}
$$

Equation (19) and (20) ensure that the power flow on a line $l$ does not exceed the capacity boundaries of the line $\operatorname{cap}_{l}^{\text {line }}$. As the flow in the electricity network is undirected, i.e. electricity flows can be either positive or negative, these equations bound the line flow in either directions. $P C_{l}^{+}$and $P C_{l}{ }_{l}$ are the corresponding scarcity prices of line capacity. The first-order condition of the system operator is given as:

$$
\sum_{l} P T D F_{l e}\left(P C_{l}^{+}-P C_{l}^{-}\right)=P T_{e}^{e l} \quad \perp \quad Y_{e} \text { free } \quad \forall \mathrm{e} \in \mathrm{E}
$$

together with equation (19) and (20). Condition (21) states that the transport price $P T_{e}^{e l}$ from/to the hub to/from any node $P T_{e}^{e l}$ is defined by the PTDF-weighted scarcity prices on transmission capacity. Final consumers are represented by a linear demand curve:

$$
D E M_{e}^{e l}=a_{e}^{e l}+b_{e}^{e l}\left(P T_{e}^{e l}+P H U B\right) \perp D E M_{e}^{e l} \quad \forall \mathrm{e} \in \mathrm{E}
$$

where $D E M_{e}^{e l}$ is the electricity demand, $P H U B$ and $P T_{e}$ yield the price at $e$ and $a_{e}^{e l}\left(b_{e}^{e l}\right)$ are strictly positive (non-positive) constants.

The electricity model includes three market clearing conditions. The transmission prices $P T_{e}$ are determined by the system operator's market clearing. At any node the energy injected or withdrawn from the grid must equal the difference between generation and demand:

$$
Y_{e}=\sum_{i} X_{i e}^{e l}-D E M_{e}^{e l} \perp P T_{e}^{e l} \text { free } \quad \forall \mathrm{e} \in \mathrm{E}
$$

Note that the market clearing condition (23) is formulated as equality which causes the price to be free in sign. This expresses the fact that electricity cannot be disposed due technical reasons. Therefore it is often denoted as an energy balance equation.

The system marginal price $P H U B$ is determined by the overall electricity market clearing equation balancing supply given by the electricity producers and demand:

$$
\sum_{i, e} X_{i e}^{e l} \geq \sum_{e} D E M_{e}^{e l} \perp \quad P H U B \geq 0
$$


Denoting the exogenously given supply of carbon emission allowances at node $e$ by $E_{e}{ }^{\max }$, the carbon price at a node is determined by the following market clearing condition: ${ }^{11}$

$$
E_{e}^{\max } \geq \sum_{e, f: \eta_{f i e}>0} \frac{\theta_{f} P_{e}^{e m i}}{\eta_{f i e}} X_{i e}^{e l} \quad \perp \quad P_{e}^{e m i} \geq 0 \quad \forall \mathrm{e} \in \mathrm{E}
$$

The full electricity model consists of equation (17) to (25).

\subsection{Combining energy networks}

Two steps are necessary to combine the models. First, we need to identify which nodes of the gas network are also nodes of the electricity network. Second, we need to make the demand in the gas network and the natural gas price in the electricity model endogenous. In Fig. 1 the interaction of the two markets is depicted by an additional fuel market in which natural gas traders are suppliers and electricity producers represent the demand. In our setting, other fuel prices (i.e. oil and coal) are externally defined. They can also be included as full market representation linked to the electricity and other resource markets via the fuel market element.

For the first step we assume that natural gas is supplied to each electricity generator, and that it is also delivered to non-electricity nodes. We establish a mapping (i.e. a two dimensional tuple) between the set of natural gas and electricity nodes denoted as $G E(g, e)$ and associate each electricity node to exactly one natural gas node. However, one natural gas nodes may serve various electricity nodes. At the electricity generation nodes, natural gas demand consists of the demand of electricity generators and further residential demand. Accordingly, generators' demand is added to the natural gas demand market clearing equation (15). Denoting the natural gas plant as gas $C I$ and natural gas as fuel also by gas $C F$, the natural gas demand market clearing equation at electricity generation nodes becomes:

$$
\sum_{h} T_{h g}^{g a s} \geq D E M_{g}^{\text {gas }}+\sum_{e \in G E(g, e)} \frac{X_{g a s, e}^{e l}}{\eta_{g a s, g a s, e}} \quad \perp \quad P D_{g}^{g a s} \geq 0 \quad \forall g \in G
$$

We now endogenize the natural gas price in the electricity model by replacing the electricity producers' zero profit condition (18) with a version with the natural gas price as a variable. For natural gas plants the equation becomes: ${ }^{12}$

$$
\frac{\sum_{g \in G E(g, e)} P D_{g}^{g a s}+\theta_{i} P E_{e}}{\eta_{g a s, i e}}+P C_{e}^{e l} \geq P T_{e}^{e l}+P H U B \quad \perp \quad X_{i e}^{e l} \geq 0 \quad \forall \mathrm{e} \in E, i \in\{\text { gas }\}
$$

For non-natural gas plants, the electricity producers' zero profit condition remains the same:

\footnotetext{
${ }^{11}$ We formulate the general model with an emission restriction at every node. However, the modification for allowing allowances trade between generators located at different nodes is straightforward by introducing a subset of the electricity node set $e$ which determines generators allowed to trade. In turn, the emission price in the zero profit condition (18) is replaced by the price of the respective trading system.

${ }^{12}$ Note that this assumes that each electricity node is served by exactly one natural gas node such that the sum on the left side includes exactly one element.
} 


$$
\frac{p f_{f e}+\theta_{f} P E_{e}}{\eta_{f i e}}+P C_{e}^{e l} \geq P T_{e}^{e l}+P H U B \quad \perp \quad X_{i e}^{e l} \geq 0 \quad \forall \mathrm{e} \in E, i \in I \backslash\{\text { gas }\}(
$$

The difference between equation (27) and (28) is that the natural gas price in (27) is endogenously determined by equation (26) while in (28) fuel prices are exogenously given. The combined model consists of equation (2) to (28) without equation (15) and (18).

Two basic assumptions drive the combination of the two network models. First, we assume that the node from which electricity producers obtain natural gas is exogenously given by the mapping $G E(g, e)$. Therefore, we obtain possibly different nodal prices in the natural gas model. Relaxing this assumption would require specifying the choice mechanism of the electricity producers at which node to buy gas and would lead to natural gas price convergence between the nodes. Second, we assume that the cross-price elasticity between natural gas and electricity in final demand equals zero. Therefore, the combined model maintains the final demand equations of the single models. The validity of this second assumption depends on the time framework chosen. While in the short run a cross-price elasticity of zero seems to be reasonable, in the long run substitution effects in final demand may occur.

The model is formulated as an MCP in the General Algebraic Modeling System (GAMS; Brook et al., 2008) and solved using the PATH (Ferris and Munson, 2000) solver.

\subsection{Restrictions and possible extensions of the basic model setting}

While the presented natural gas model is static, we can extend it to include storage by adding the zeroprofit condition of the storage operator and the respective demand and supply to the market clearing equation (14) and (15). Natural gas markets are partly characterized by long-term contracts and oilprice coupled prices. For long-term contracts, parameters reflecting the contracted quantities can be added to the natural gas producers' program with a new constraint which states that the produced quantity must exceed the contracted quantity. Consequently, only extraction exceeding the contracted quantity enters the market clearing equation. Similarly, we can add the long-term contract to the demand side. Since we have formulated the model in a complementarity framework, i.e. as an equilibrium model, prices are explicitly represented. Therefore, it is simple to include oil price indexation by adding constraints on the natural gas price. Assuming constant unit costs for all market participants and linear demand, we develop the model as a linear complementarity model. The restriction of linearity can be relaxed by putting other demand functions into equation (13) and replacing the constant unit costs by some marginal cost functions.

Our electricity model is also static. Therefore, pumped storage facilities are not regarded, but could easily be added by including the zero-profit condition of the storage operator and the respective demand and supply to the market clearing equation. While we do not include losses in the basic framework, we can easily add them, e.g. by including a piecewise linear representation. They will be important when estimating the potential for substituting fuel transport and electricity transmission for long distances. The linear demand function is supposed to represent a medium- to long-term demand 
behavior. Note that a completely inelastic demand function can be used when modeling a shorter term. Similar to the natural gas market, different functional forms can also be used if the linearity assumption is relaxed.

Finally, we assume perfect competition and, accordingly, representative agents. While it is possible to relax this assumption for one group of market participants under simultaneous model timing, introducing sequential timing will result in mathematical or equilibrium problems with equilibrium constraints (M/EPEC).

\section{Sample application}

\subsection{Parameterization and scenarios}

In our application, the basic model parameters are taken from Neumann et al. (2009) for the gas market representation and from Leuthold et al. (2008) for the electricity market. The model is designed as a sample application highlighting the interaction of natural gas and electricity markets .

The combined model covers the natural gas and electricity demand of central and western European countries (Fig. 2). Whereas the gas model also includes the UK, Ireland, Norway and Sweden as demand nodes and several exporting nodes outside Europe (e.g., Russia, Algeria, and Libya), the electricity market representation is limited to the continental European countries. Both markets are represented in a highly stylized setting with one node representing the respective country. In the natural gas market, cross-border transmission is modeled by single connections between country nodes (upper half, Fig. 2) differentiating between European pipelines connecting countries associated with natural gas demand and Non-European pipelines providing a representation of the relevant import connections. Including LNG routes indicates the possible connections between liquefaction and regasification nodes. In the electricity market, countries are connected to cross-border nodes via tielines (lower half, Fig. 2). These cross-border nodes connect according to the European transmission network. This approach accounts for congestion between countries but not within them.

The model is based on 2005 values (see Table 5 in the Appendix). The time resolution is limited to an average hour not taking account of seasonal or daily demand and production patterns. Natural gas and electricity demand are taken from Eurostat (2010). Demand is assumed to be linear based on reference demand and price values with an elasticity at this reference point of -0.5 for natural gas and -0.25 for electricity. Electricity generation is clustered in nine technologies based on UCTE (2007): nuclear, lignite, coal, gas, oil, mixed, other, hydro, and pumped storage. ${ }^{13}$ The Appendix shows the underlying assumptions regarding fuel prices, efficiency and emission factors (Table 4). We do not account for spatial differences in those values. We assume a merit order in which coal-fired units are cheaper than gas or oil-fired ones in the absence of emission prices.

\footnotetext{
${ }^{13}$ Mixed generation represents a large variety of multi-fuel engines operating on coal and/or gas and/or oil. We do not consider their demand as part of the natural gas demand.
} 
We analyze three different scenarios to highlight the interaction between the linked markets. First, we derive a Base case using the dataset as the benchmark. Second, we analyze the impact of a change in the natural gas market on the system (Russian case). We assume a sharp reduction in exports from Russia via the Ukraine to a level of about $50 \%$ of the base case exports. This will lead to supply shortages in South-East Europe, impact the natural gas flow and price pattern, and possibly electricity generation. Third, we analyze the reverse interaction due to a change in the electricity market setting by introducing emission trading (Emission case). Taking the base case emissions as the benchmark, we require a $15 \%$ emission reduction target. The resulting emission allowance price will lead to a reduction of the cost advantage of coal in favor of natural gas which increases the demand for the latter and impacts the natural gas market. 
Fig. 2 Networks

\section{Natural Gas Network}

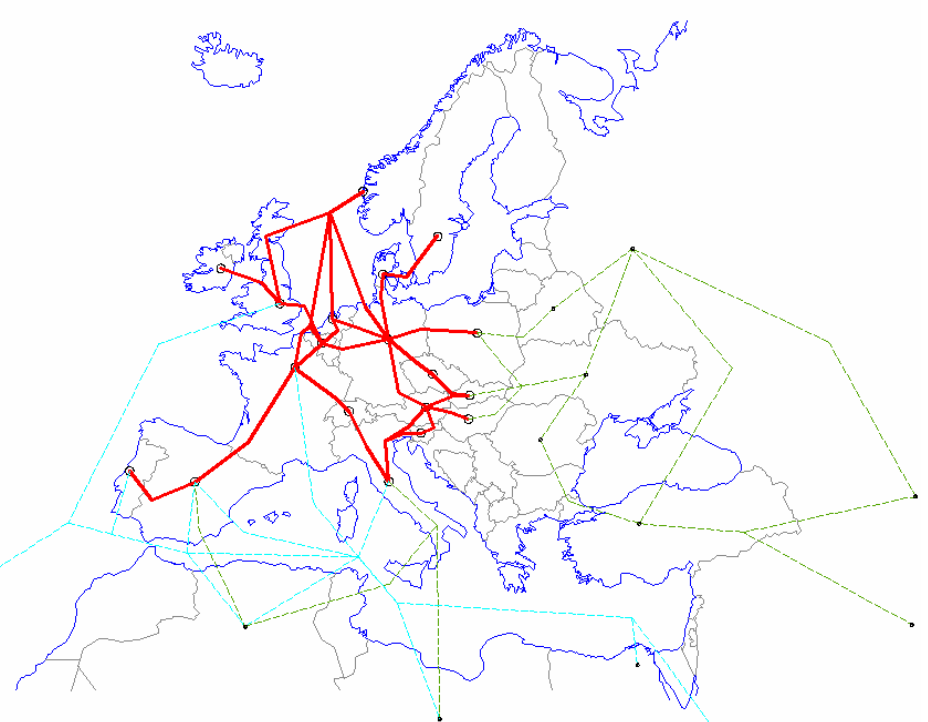

\section{European pipelines Non-European pipelines}

LNG routes

\section{Electricity Network}

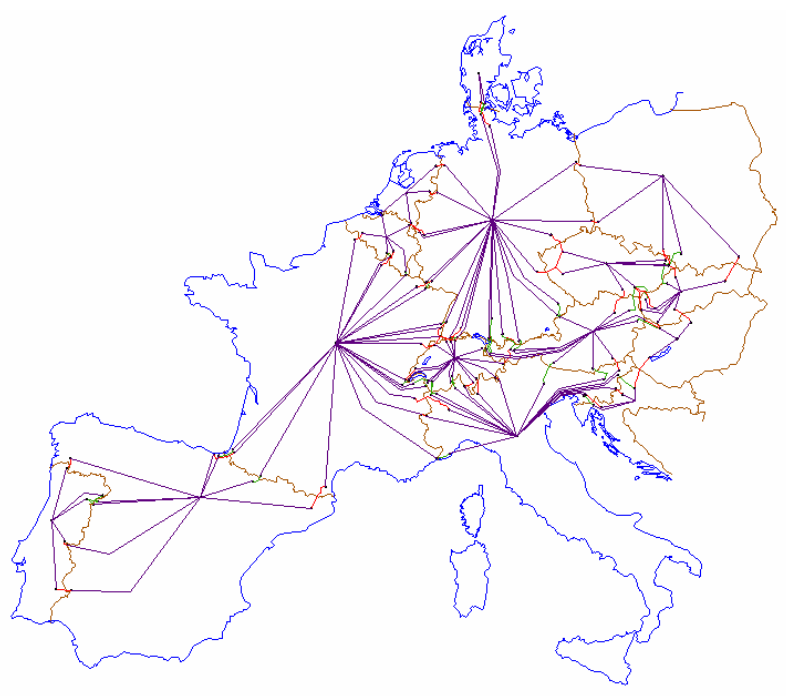

Country tie lines

$380 \mathrm{kV}$ cross border line

$220 \mathrm{kV}$ cross border line

Source: Based on Neumann et al. (2009) and Leuthold et al. (2008)

\subsection{Result overview}

The results presented in Table 2 and Table 3 provide the price outcomes for the natural gas and electricity markets for the three scenarios and the electricity generation by fuel. See the Appendix for a graphic representation of the obtained results highlighting country prices and network congestion.

The basic model outcomes are in line with our expectations. In the Base case the natural gas market is roughly clustered into three supply regions: Western and Central Europe are largely supplied with natural gas from the North Sea (Norway and the Netherlands); Eastern Europe is supplied by Russia; 
and Southern Europe is supplied by Africa (Algeria and Libya). We see a similar price pattern in the electricity market. Spain and Portugal are a separate price zone due to congestion between France and Spain (Table 2). Italy is the "electricity sink" of Europe which consequently leads to a high price level and congestion at the cross-border lines. Northern and Eastern Europe are more or less on a coal-based price level. The generation pattern follows the merit order with hydro, nuclear, and lignite being fully utilized (Table 3).

In the Russian case the imports via the Ukraine are significantly reduced which leads to higher natural gas prices in South East Europe (Table 2). The situation in North and West Europe resembles the Base case because the North Sea gas and the Russian imports via Belarus and Poland are not affected. In the electricity market countries facing higher gas prices in general also face higher electricity prices.

In the Emission case the allowed total emissions are cut to $85 \%$ of the emissions in the base case. Due to the binding emission cap an allowance price of about $5.5 € / t_{\mathrm{CO} 2}$ occurs and consequently electricity prices increase on average (Table 2). Gas-based electricity production increases to about $45 \mathrm{GW}$ while coal drops to $30 \mathrm{GW}$ (Table 3). This leads to a general increase in demand for natural gas and on average to higher domestic gas prices across Europe. Since LNG capacities are already fully utilized in the Base case, none of the scenarios affect LNG trade patterns.

Table 2: Demand price outcomes [€/MWh]

\begin{tabular}{|c|c|c|c|c|c|c|}
\hline \multirow[b]{2}{*}{ Country } & \multicolumn{2}{|c|}{ Base case } & \multicolumn{2}{|c|}{ Russian case } & \multicolumn{2}{|c|}{ Emission case } \\
\hline & Natural gas & Electricity & Natural gas & Electricity & Natural gas & Electricity \\
\hline Austria & 8.46 & 18.86 & 11.26 & 19.32 & 8.46 & 24.17 \\
\hline Belgium & 8.40 & 18.91 & 8.42 & 18.23 & 8.73 & 23.34 \\
\hline Czech Republic & 8.29 & 17.35 & 8.31 & 17.40 & 8.46 & 23.33 \\
\hline Denmark & 6.64 & 17.14 & 6.66 & 17.14 & 6.97 & 23.21 \\
\hline France & 8.95 & 16.21 & 8.97 & 15.98 & 9.28 & 17.39 \\
\hline Germany & 7.74 & 17.14 & 7.76 & 17.14 & 8.07 & 23.21 \\
\hline Hungary & 8.34 & 20.84 & 10.05 & 21.63 & 8.92 & 25.33 \\
\hline Ireland & 8.40 & & 8.42 & & 8.73 & \\
\hline Italy & 9.78 & 24.44 & 10.29 & 25.71 & 9.78 & 27.47 \\
\hline Netherlands & 7.08 & 18.14 & 7.10 & 17.76 & 7.41 & 23.28 \\
\hline Norway & 5.76 & & 5.78 & & 6.09 & \\
\hline Poland & 6.24 & 17.14 & 6.24 & 17.14 & 6.24 & 23.21 \\
\hline Portugal & 9.27 & 23.18 & 9.27 & 23.18 & 8.46 & 24.19 \\
\hline Slovakia & 7.69 & 16.88 & 10.49 & 16.81 & 7.69 & 23.06 \\
\hline Slovenia & 9.12 & & 11.50 & & 9.12 & \\
\hline Spain & 9.27 & 23.18 & 9.27 & 23.18 & 8.46 & 24.19 \\
\hline Sweden & 7.74 & & 7.76 & & 8.07 & \\
\hline Switzerland & 9.01 & 14.75 & 9.52 & 15.05 & 9.01 & 24.33 \\
\hline UK & 7.74 & & 7.76 & & 8.07 & \\
\hline
\end{tabular}


Table 3: Electricity generation [MW]

\begin{tabular}{|c|c|c|c|c|c|c|}
\hline & Hydro & Nuclear & Lignite & Coal & Gas & Mixed \\
\hline \multicolumn{7}{|l|}{ Base Case } \\
\hline Germany & 2335 & 18270 & 18270 & 17857 & 0 & \\
\hline Benelux & 47 & 5603 & 0 & 3968 & 14712 & \\
\hline France & 9585 & 56970 & 0 & 0 & 0 & \\
\hline Eastern Europe & 1352 & 7106 & 15861 & 14239 & 2554 & \\
\hline Alps & 10554 & 2880 & 0 & 1573 & 90 & \\
\hline Italy & 6075 & 0 & 0 & 4230 & 16931 & \\
\hline Iberia & 7876 & 6712 & 3082 & 8418 & 5468 & \\
\hline \multicolumn{7}{|l|}{ Russian Case } \\
\hline Germany & 2335 & 18270 & 18270 & 21864 & 0 & \\
\hline Benelux & 47 & 5603 & 0 & 3968 & 14510 & \\
\hline France & 9585 & 56970 & 0 & 0 & 0 & \\
\hline Eastern Europe & 1352 & 7106 & 15861 & 11274 & 668 & \\
\hline Alps & 10554 & 2880 & 0 & 1573 & 90 & \\
\hline Italy & 6075 & 0 & 0 & 4230 & 5193 & 12108 \\
\hline Iberia & 7876 & 6712 & 3082 & 8418 & 5468 & \\
\hline \multicolumn{7}{|l|}{ Emission Case } \\
\hline Germany & 2335 & 18270 & 18270 & 2861 & 5640 & \\
\hline Benelux & 47 & 5603 & 0 & 3968 & 14712 & \\
\hline France & 9585 & 56970 & 0 & 0 & 0 & \\
\hline Eastern Europe & 1352 & 7106 & 15861 & 11795 & 3457 & \\
\hline Alps & 10554 & 2880 & 0 & 1573 & 197 & \\
\hline Italy & 6075 & 0 & 0 & 4230 & 15618 & \\
\hline Iberia & 7876 & 6712 & 3082 & 8418 & 5034 & \\
\hline
\end{tabular}

\subsection{Feedback effects and discussion}

The two counterfactual scenarios represent the two possible feedback directions: In the Russian case natural gas prices increase which results in downstream adjustments in the electricity market and in the emission case a shift in generation dispatch leads to a higher natural gas demand. Despite the direct feedback effects, the network topology of both markets causes other impacts.

In the downstream feedback situation (Russian Case) the basic feedback is as expected: the drop in imports from Russia via the southern route including Ukraine, Hungary and Slovakia leads to significant price increases in these countries which in turn reduces gas-based electricity production (Table 3). We observe other side effects, e.g. Hungary becomes an electricity importer, which changes East Europe's electricity flow pattern. To replace the reduced gas generation in Hungary the cheapest alternative is coal energy from northern countries. However, Polish coal generation, although possible from a generation capacity point of view, cannot be utilized due to congestion between Hungary and Slovakia. Therefore, Germany increases its coal generation to meet Hungarian demand. But this changes the power flow pattern via Austria towards Italy. As a result Germany increases its coal production beyond the Hungarian demand, and in turn, Poland reduces its generation to allow more 
power flow to import-dependent Italy. ${ }^{14}$ A side effect of the increased coal generation in Germany is the reduction in imports via the Netherlands. Therefore, the available Dutch natural gas generation capacities can be slightly shifted to satisfy a larger fraction of the Belgian demand and relieve congestion at the Benelux borders. Consequently, the price level in the Benelux drops slightly (Table 2).

In the upstream feedback case (Emission Case) the binding emission target causes a switch from the most emission-intensive coal technology to the least-intensive gas technology. Coal production drops in those countries able to compensate for the fallback by increasing imports or switching to gas-based production. Most of the reduction occurs in Germany where about $15 \mathrm{GW}$ of coal generation is shut, followed by Poland with about $2 \mathrm{GW}$. Since the carbon price adds to the cost of electricity generation, the electricity price increases and demand decreases. Therefore, the $5 \mathrm{GW}$ increase of gas-based generation does not outweigh the decrease in coal- based generation. Domestic natural gas prices increase in most countries by $4 \%$ to $7 \%$, even in countries that are not included in our electricity market representation. However, most East European countries do not face a price increase because they can either increase their imports from Russia (Slovakia and Czech Republic) or they do not rely on natural gas generation (Poland).

We observe a network-induced feedback in the Iberian Peninsula where the price of natural gas drops as a result of an isolated network situation. The Iberian Peninsula's electricity imports from France are bounded by the low capacities in the Pyrenees, and its gas imports are bounded by its LNG terminals and connection to Africa. Thus, the introduction of emission trading does not influence the trade pattern in either energy market. However, the electricity price increase does cause a slight reduction in electricity demand. As the emission price is not high enough, natural gas-fired generation is still the marginal technology in the merit order. Therefore, the output of these plants is reduced. The reduced demand for gas of the electricity sector causes a price decrease which in turn stimulates final demand. In summary, the total gas demand (consisting of domestic and electricity gas demand) does not change in Portugal and Spain.

LNG capacities are fully utilized throughout the scenarios and consequently have no further impact on the results. We note that this is likely to change, given the future projected extension of LNG regasification capacities in Europe (Rüster, 2010). As LNG provides a flexible alternative to pipeline transport, a change in the pipeline flow pattern as in the Russian case could lead to changes in the LNG submarket. Depending on the available liquefaction capacities it could either lead to increased imports in the respective region (e.g. Italy) or in the case of restricted liquefaction capacities to a switch in the LNG import pattern from one region to another due to the altered price level (e.g. less LNG imports in Spain and rerouted to Italy). The latter situation would then produce further impacts on the natural gas and electricity markets far from the original cause (e.g., Russian export cut).

\footnotetext{
${ }^{14}$ Coal prices and power plant efficiencies are not locational differentiated. Thus, the only cost difference between Polish and German coal production is its impact on the network.
} 
Although the presented results greatly depend on the chosen dataset, particularly the underlying fuel price assumptions, our scenarios highlight the possible interactions of natural gas and electricity network markets. The fuel connection of gas as an input factor of electricity generation leads to obvious results in gas price levels or altering generation dispatch. These results can easily be captured by an energy system model or corresponding parameter assumptions. The value added of our models is the combination of a full network market representation of both markets, because we capture effects that are not obvious on first sight. Congestion between markets and particular effects due to loopflows in electricity markets can lead to price and quantity effects in markets far from the initial cause of market changes. As prices and quantities are the fundamental determinants of investment decisions, neglecting the presented impacts of network feedback could lead to a lack of or an oversupply of production capacities in some regions. Similarly, transmission capacity decisions depend on regional import and export needs which subsequently impact connected regions and markets. We suggest that neglecting the network character of those markets can result in a suboptimal market structure.

\section{Conclusion}

This paper has analyzed the interaction of natural gas and electricity markets considering the network character of both. Using the MCP format, we design equilibrium models of the respective markets. Manipulating the market clearing condition for the natural gas market, the two models are combined by interacting on a fuel market. Applying the model to a stylized representation of Europe, we show that changes in both the supply in the natural gas market and the generation dispatch in the electricity market impact the respective downstream and upstream markets beyond the pure price connection. Congestion between markets and particular effects produced by loop-flows in electricity markets can lead to price and quantity effects in markets located far from the initial cause of market changes. The results highlight the significance of undertaking a combined market assessment for market participants and the political institutions which set market and regulatory designs. Companies active in one or several energy markets need to include the network dimension in their market assessments when making investment and expansion decisions. We suggest that similar institutions responsible for setting market rules also consider the interactions. This will be particularly important for the global electricity sector since decisions such as future network extension plans, emission reduction targets, renewable integration, etc., directly influence all upstream fuel markets.

\section{Acknowledgments}

We thank Christian von Hirschhausen, Sophia Rüster, and participants of the YEEES meeting April 2010 in Cambridge, UK, and the editor and referees for their comments and suggestions. 


\section{References}

An, S., Q. Li, and T. W. Gedra. (2003) Natural Gas and Electricity Optimal Power Flow. IEEE PES

Transmission and Distribution Conference and Exposition, Dallas, Texas, Sept. 7-12.

Arnold, M. and G. Andersson (2008) Decomposed Electricity and Natural Gas Optimal Power Flow.

16th PSCC, Glasgow, Scotland, July 14-18.

Aune, F. R., R. Golombek, S. A. C. Kittelsen, K. E. Rosendahl, and O. Wolfgang (2001) LIBEMOD LIBEralisation MODel for the European Energy Markets: A Technical Description. Ragnar Frisch Centre for Economic Research, Working Paper 1/2001. http://www.frisch.uio.no/pdf/arbnot01 01.pdf. Accessed 15.01.2010.

Bauer, N. et al. (2008) REMIND: The equations. Potsdam Institute for Climate Impact Research (PIK). http://www.pik-potsdam.de/research/research-domains/sustainable-solutions/esmgroup/remind-code. Accessed 15.01.2010.

Brooke, A., D. Kendrick, and A. Meeraus (2008): GAMS A User's Guide. Washington, GAMS Development Cooperation.

Capros, P., P. Georgakopoulos, D. Van Regemorter, S. Proost, and C. Schmidt (1997) The GEM-E3 General Equilibrium of the European Union. Economic and Financial Modeling: 21-160.

Egging, R., S. A. Gabriel, F. Holz, and J. Zhuang (2008) A Complementarity Model for the European Natural Gas Market. Energy Policy 36(7):2385-2414.

Eurostat (2010) Energy Statistics - Supply, Transformation, Consumption.

http://epp.eurostat.ec.europa.eu/portal/page/portal/energy/data/database. Accessed 15.01.2010.

Ferris, M. C. and T. S. Munson (2000) Complementarity Problems in GAMS and the Path Solver. Journal of Economic Dynamics and Control 24(2):165-188.

Gabriel, S. A., J. Zhuang, S. Kiet (2005) A large-scale linear complementarity model of the North American natural gas market. Energy Economics 27(4):639-665.

Green, R. (2007) Nodal Pricing of Electricity: How Much Does It Cost to Get It Wrong? Journal of Regulatory Economics 31(2):125-149.

Grübler, A. and S. Messner (1998) Technological Change and the Timing of Mitigation Measures. Energy Economics 20(5-6):495-512.

Hobbs, B. F. (2001) Linear Complementarity Models of Nash-Cournot Competition in Bilateral and POOLCO Power Markets. IEEE Transactions on Power Systems 16(2):194-202.

Holz, F. (2009) Modeling the European Natural Gas Market - Static and Dynamic Perspectives of an Oligopolistic Market. Dissertation, TU Berlin.

IPCC (2006) 2006 IPCC Guidelines for National Greenhouse Gas Inventories. Ed. H. S. Eggleston, L. Buendia, K. Miwa, T. Ngara, and K. Tanabe. Institute for Global Environmental Strategy. Kouvaritakis, N., A. Soria, and S. Isoard (2004) Modelling Energy Technology Dynamics: Methodology for Adaptive Expectations Models with Learning by Doing and Learning by Searching. International Journal of Global Energy Issues 14(1-2):104-115. 
Leuthold, F., H. Weigt, and C. von Hirschhausen (2008) ELMOD - A Model of the European Electricity Market. Dresden University of Technology Electricity Market Working Papers WPEM-00.

Lochner, S. and D. Bothe (2007) Nord Stream-Gas, quo vadis? Analyse der Ostseepipeline mit dem TIGER-Modell. Energiewirtschaftliche Tagesfragen 57(11):18-23.

Loulou, R., G. Goldstein, and K. Noble et al. (2004) Documentation for the MARKAL Family of Models.

Mathiesen, L. (1985) Computational Experience in Solving Equilibrium Models by a Sequence of Linear Complementarity Problems. Operations Research 33(6):1125-1250.

Mathiesen, L., K. Roland, and K. Thonstad (1987) The European natural gas market: Degrees of market power on the selling side. In: Rolf Golombek, Michael Hoel, and Jon Vislie, editors, Natural Gas Markets and Contracts, Contributions to Economic Analysis: 27-58. North-Holland.

Möst, D. and H. Perlwitz (2009) Prospects of Gas Supply until 2020 in Europe and its Relevance for the Power Sector in the Context of Emission Trading. Energy 34(10):1510-1522.

Neuhoff, K., J. Barquin, M. G. Boots, A. Ehrenmann, B. F. Hobbs, A.M. Rijkers, and M. Vásquez (2005) Network-constrained Cournot Models of Liberalized Electricity Markets: The Devil is in the Details. Energy Economics 27(3):495-525.

Neumann, A., N. Viehrig, and H. Weigt (2009) InTraGas - A Stylized Model of the European Natural Gas Network. Dresden University of Technology Resource Markets Working Paper WP-RM-16.

O'Neil, R. P., P. M. Sotkiewicz, B. F. Hobbs, M. H. Rothkopf, and W. R. Stewart Jr. (2005) Efficient Market-Clearing Prices in Markets with Nonconvexities. European Journal of Operations Research 164:296-285.

Paltsev, S., J. M. Reilly, H. D. Jacoby, R. S. Eckaus, J. McFarland, M. Sarofim, M. Asadoorian, and M. Babiker (2005) The MIT Emission Prediction and Policy Analysis (EPPA) Model: Version 4. MIT Joint Program on the Science and Policy of Global Change Report 125.

Perner, J. and A. Seeliger (2004) Prospects of Gas Supplies to the European Market until 2030 Results from the Simulation Model EUGAS. Utilities Policy 12(4):291-302.

Rüster, S. (2010): Recent Dynamics in the Global Liquefied Natural Gas Industry. Dresden University of Technology Resource Markets Working Papers WP-RM-19.

Rutherford, T. F. (1995) Extension of GAMS for Complementarity Problems Arising in Applied Economic Analysis. Journal of Economic Dynamics and Control 19(8):1299-1324.

Smeers, Y. (1997) Computable Equilibrium Models and the Restructuring of the European Electricity and Gas Markets. Energy Journal 18(4):1-31.

Stigler, H. and C. Todem (2005) Optimization of the Austrian Electricity Sector (Control Zone of VERBUND APG) under the Constraints of Network Capacities by Nodal Pricing. Central European Journal of Operations Research 13:105-125. 
UCTE (2007) System Adequacy Forecast, SAF 2006-2015: Scenarios.

http://www.entsoe.eu/fileadmin/user_upload/_library/publications/ce/systemadequacy/saf/UCTE SAF 2006-2015 scenarios.zip. Accessed 15.01.2010.

Unsihuay, C., J. W. M. Lima, and A. C. Z. de Souza (2007) Modeling the Integrated Natural Gas and Electricity Optimal Power Flow. IEEE Power Engineering Society General Meeting, Tampa, Florida, June 24-28.

Ventosa, M., Á. Baíllo, A. Ramos, and M. Rivier (2005) Electricity Market Modeling Trends. Energy Policy 33(7):897-913. 


\section{Appendix}

Table 4: Electricity generation specifications

\begin{tabular}{l|ccc}
\hline \multicolumn{1}{c|}{ Technology } & $\begin{array}{c}\text { Fuel price } \\
{\left[\in / \mathrm{MWh}_{\mathrm{th}}\right]}\end{array}$ & Efficiency & $\begin{array}{c}\mathrm{CO}_{2} \text { emissions } \\
{\left[\mathrm{t} / \mathrm{MWh}_{\mathrm{th}}\right]}\end{array}$ \\
\hline nuclear & 3 & $30 \%$ & 0.00 \\
lignite & 5 & $35 \%$ & 0.36 \\
coal & 6 & $35 \%$ & 0.35 \\
gas & endogenous & $40 \%$ & 0.20 \\
oil & 10 & $35 \%$ & 0.28 \\
mixed & 9 & $35 \%$ & 0.28 \\
other & 12 & $35 \%$ & 0.35 \\
hydro & 0 & $100 \%$ & 0.00 \\
pumped storage & 25 & $75 \%$ & 0.00 \\
\hline
\end{tabular}

Source: IPCC (2006), own assumptions

Table 5: Dataset

\begin{tabular}{|c|c|c|c|c|c|}
\hline Country & $\begin{array}{c}\text { Natural gas } \\
\text { demand } \\
{[\mathrm{GW} \text { per } \mathrm{h}]}\end{array}$ & $\begin{array}{c}\text { Electricity } \\
\text { demand } \\
{[\mathrm{GW} \text { per } \mathrm{h}]}\end{array}$ & $\begin{array}{c}\text { Natural gas } \\
\text { capacities } \\
{[\mathrm{GW}]}\end{array}$ & $\begin{array}{c}\text { Electricity } \\
\text { capacities } \\
{[\mathrm{GW}]} \\
\end{array}$ & $\begin{array}{c}\mathrm{LNG} \\
\text { capacities } \\
{[\mathrm{GW}]} \\
\end{array}$ \\
\hline Austria & 12.1 & 7.2 & 1.5 & 18.2 & \\
\hline Belgium & 21.8 & 10.0 & & 15.4 & 4.5 \\
\hline Czech Republic & 11.4 & 7.2 & 0.2 & 16.2 & \\
\hline Denmark & 6.5 & 2.4 & 9.8 & 3.5 & \\
\hline France & 60.8 & 55.1 & 1.8 & 113.4 & 14.6 \\
\hline Germany & 119.6 & 63.5 & 18.6 & 101.3 & \\
\hline Hungary & 17.9 & 4.5 & 2.7 & 7.1 & \\
\hline Ireland & 5.1 & 0.0 & 0.5 & na & \\
\hline Italy & 104.5 & 37.7 & 11.3 & 86.8 & 3.5 \\
\hline Netherlands & 52.3 & 13.1 & 121.0 & 20.9 & \\
\hline Norway & 7.6 & 0.0 & 97.4 & na & \\
\hline Poland & 18.1 & 14.9 & 5.7 & 32.1 & \\
\hline Portugal & 5.6 & 5.7 & & 11.6 & 5.2 \\
\hline Slovakia & 8.8 & 3.0 & 0.1 & 7.3 & \\
\hline Slovenia & 1.4 & 1.5 & & 2.8 & \\
\hline Spain & 44.2 & 28.9 & 0.2 & 65.5 & 25.3 \\
\hline Sweden & 1.2 & 0.0 & & na & \\
\hline Switzerland & 4.1 & 7.2 & & 16.7 & \\
\hline UK & 126.5 & 0.0 & 105.1 & na & 4.5 \\
\hline
\end{tabular}

Source: Neumann et al. (2009), Leuthold et al. (2008), UCTE (2007), Eurostat (2010) 
Fig. 3 Base case, natural gas market, prices and congestion

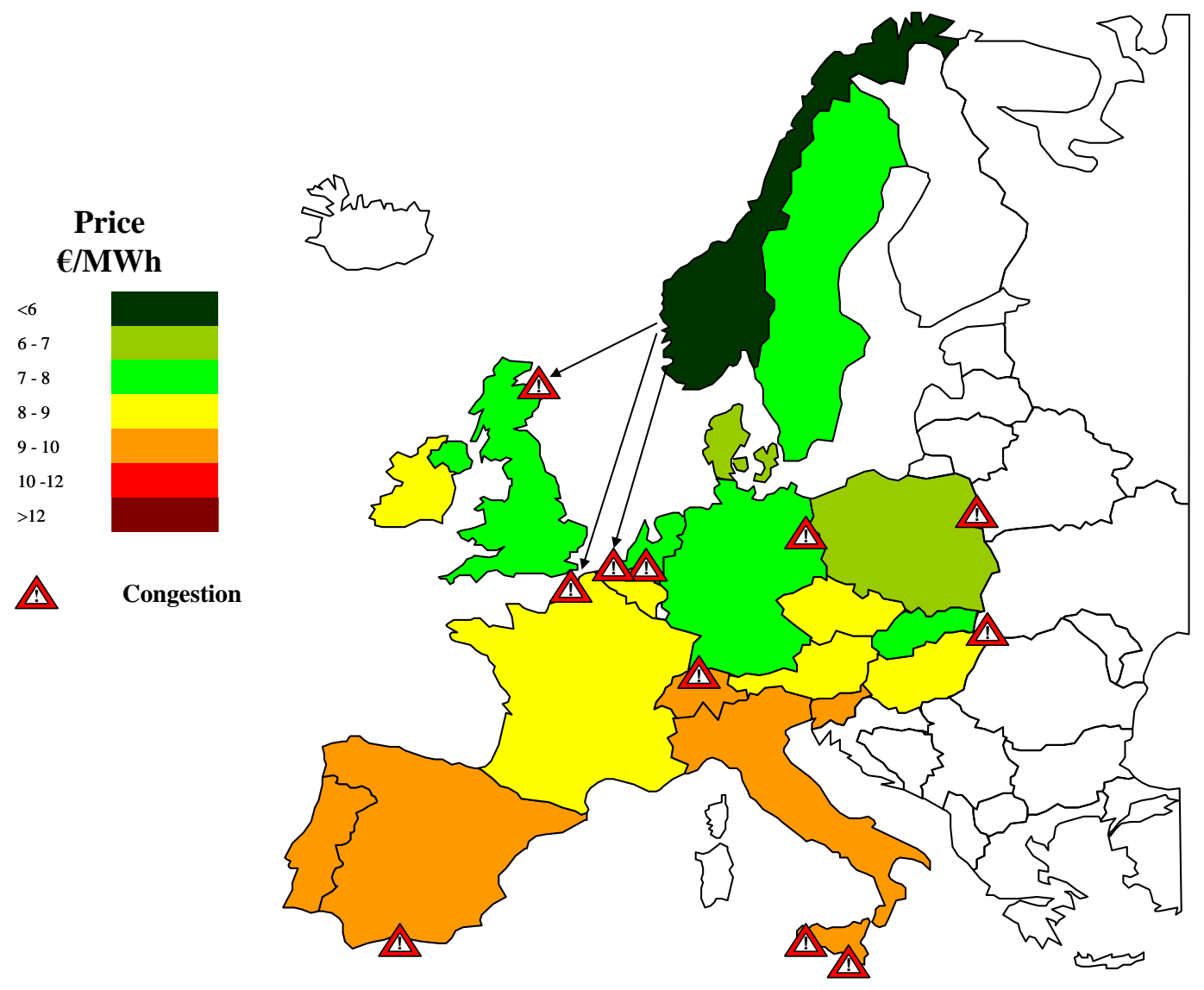

Fig. 4 Base case, electricity market, prices and congestion

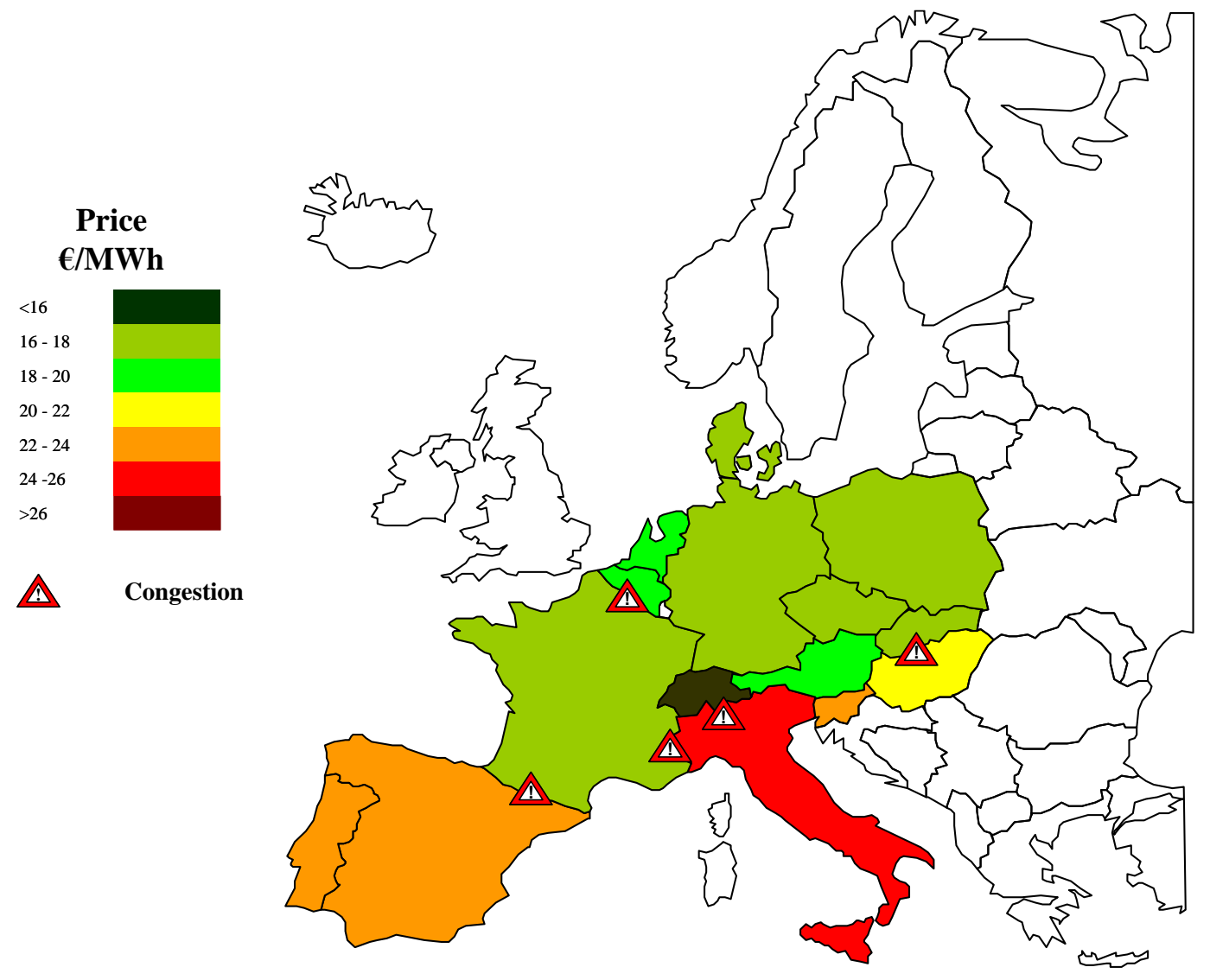


Fig. 5 Russian case, natural gas market, prices and congestion

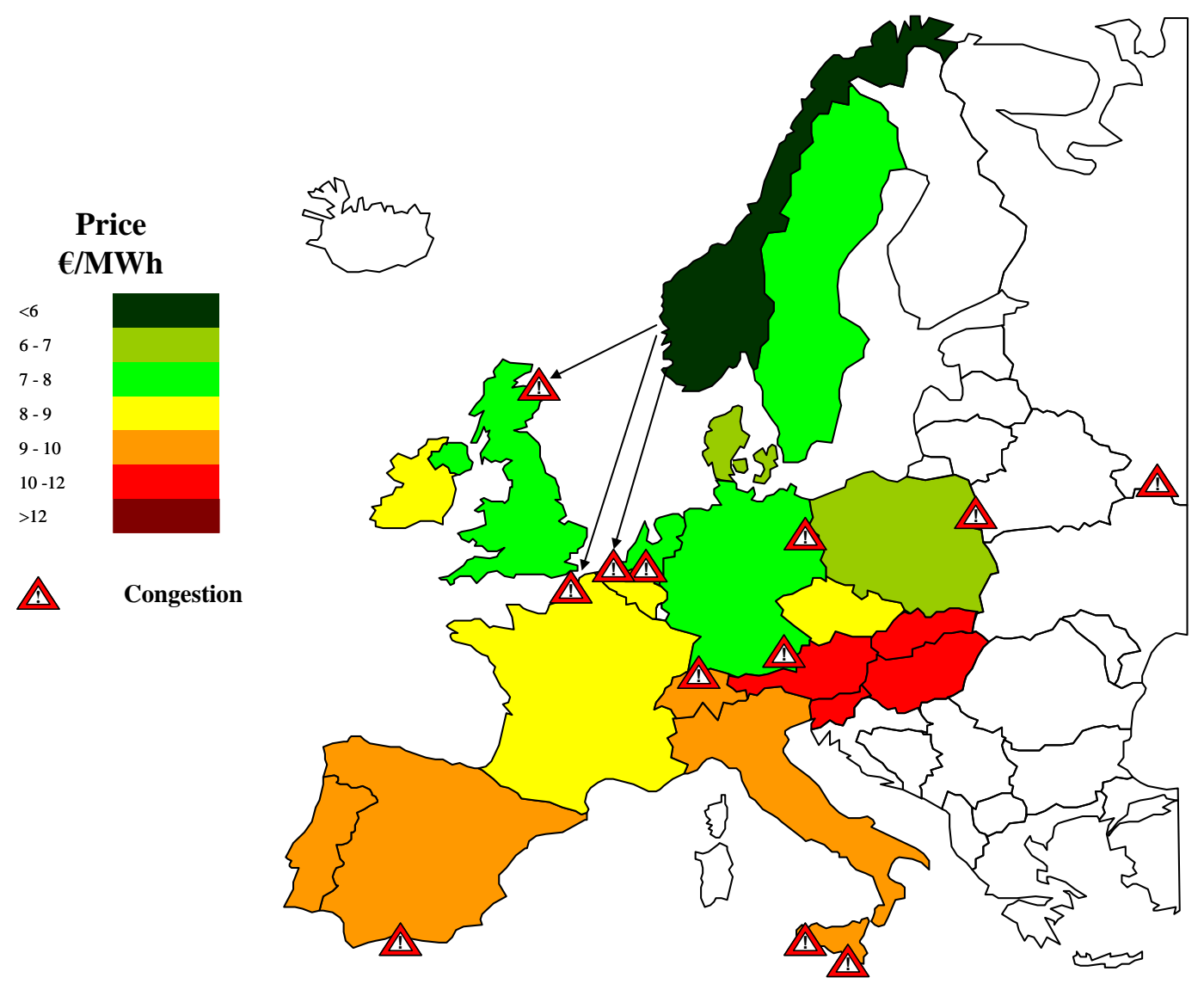

Fig. 6 Russian case, electricity market, prices and congestion

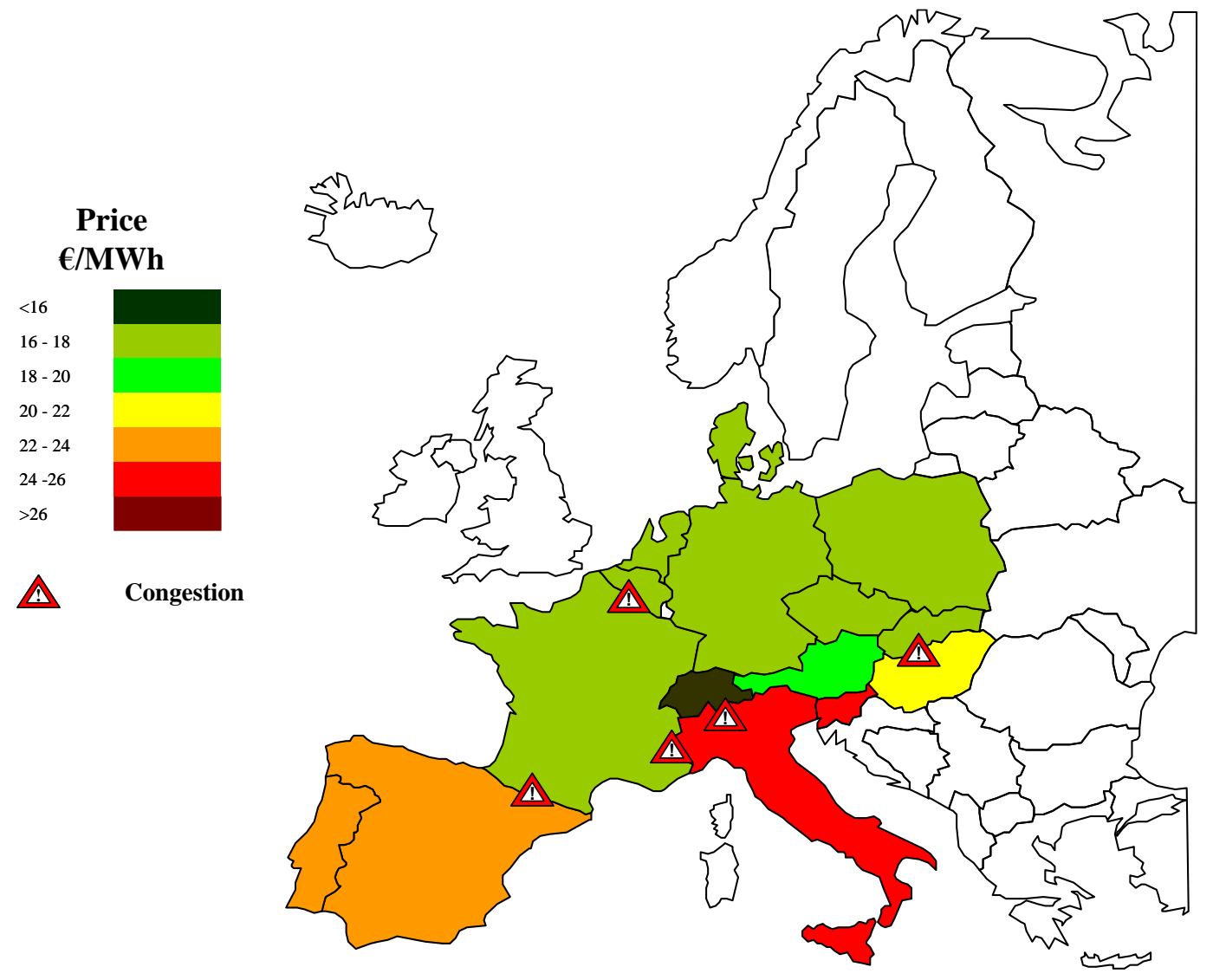


Fig. 7 Emission case, natural gas market, prices and congestion

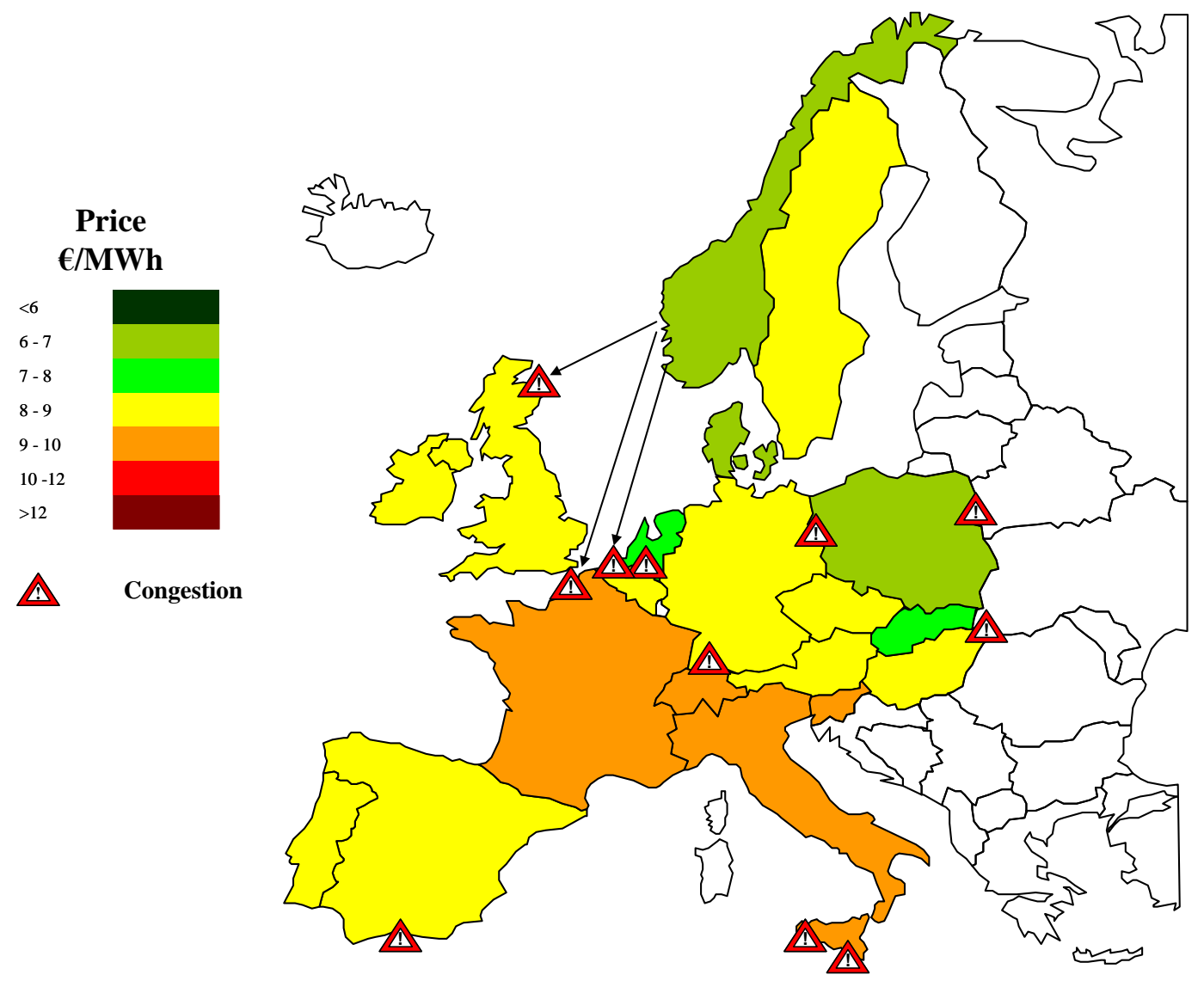

Fig. 8 Emission case, electricity market, prices and congestion

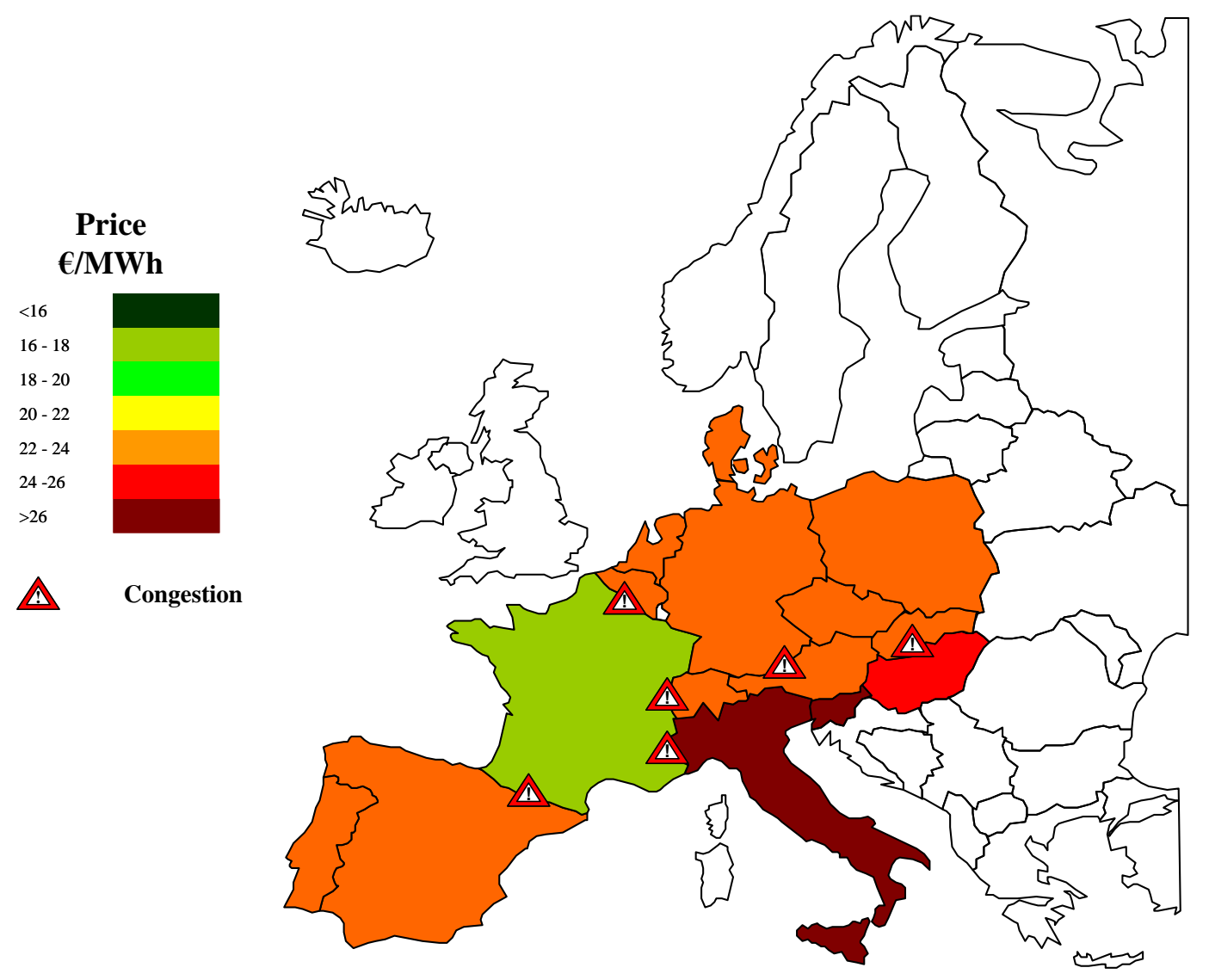




\section{Working Papers of the Center of Economic Research at ETH Zurich}

(PDF-files of the Working Papers can be downloaded at www.cer.ethz.ch/research).

16/238 J. Abrell and H. Weigt

Combining Energy Networks

16/237 J. Abrell and H. Weigt

Investments in a Combined Energy Network Model: Substitution between Natural Gas and Electricity?

16/236 R. van Nieuwkoop, K. Axhausen and T. Rutherford

A traffic equilibrium model with paid-parking search

16/235 E. Balistreri, D. Kaffine, and H. Yonezawa

Optimal environmental border adjustments under the General Agreement on Tariffs and Trade

16/234 C. Boehringer, N. Rivers, H. Yonezawa

Vertical fiscal externalities and the environment

16/233 J. Abrell and S. Rausch

Combining Price and Quantity Controls under Partitioned Environmental Regulation

16/232 L. Bretschger and A. Vinogradova

Preservation of Agricultural Soils with Endogenous Stochastic Degradation

16/231 F. Lechthaler and A. Vinogradova

The Climate Challenge for Agriculture and the Value of Climate Services: Application to Coffee-Farming in Peru

16/230 S. Rausch and G. Schwarz

Household heterogeneity, aggregation, and the distributional impacts of environmental taxes

16/229 J. Abrell and S. Rausch

Cross-Country Electricity Trade, Renewable Energy and European Transmission Infrastructure Policy

16/228 M. Filippini, B. Hirl, and G. Masiero

Rational habits in residential electricity demand

16/227 J. Abrell, S. Rausch, and H. Schwerin

Long-Run Energy Use and the Efficiency Paradox

15/226 L. Bretschger, F. Lechthaler, S. Rausch, and L. Zhang

Knowledge Diffusion, Endogenous Growth, and the Costs of Global Climate Policy 
15/225 H. Gersbach

History-bound Reelections

15/224 J.-P. Nicolai

Emission Reduction and Profit-Neutral Permit Allocations

15/223 M. Miller and A. Alberini

Sensitivity of price elasticity of demand to aggregation, unobserved heterogeneity, price trends, and price endogeneity: Evidence from U.S. Data

15/222 H. Gersbach, P. Muller and O. Tejada

Costs of Change, Political Polarization, and Re-election Hurdles

15/221 K. Huesmann and W. Mimra

Quality provision and reporting when health care services are multi-dimensional and quality signals imperfect

15/220 A. Alberini and M. Filippini

Transient and Persistent Energy Efficiency in the US Residential Sector: Evidence from Household-level Data

15/219 F. Noack, M.-C. Riekhof, and M. Quaas

Use Rights for Common Pool Resources and Economic Development

15/218 A. Vinogradova

Illegal Immigration, Deportation Policy, and the Optimal Timing of Return

$15 / 217$ L. Bretschger and A. Vinogradova

Equitable and effective climate policy: Integrating less developed countries into a global climate agreement

15/216 M. Filippini and L. C. Hunt Measurement of Energy Efficiency Based on Economic Foundations

15/215 M. Alvarez-Mozos, R. van den Brink, G. van der Laan and O. Tejada

From Hierarchies to Levels: New Solutions for Games with Hierarchical Structure

15/214 H. Gersbach

Assessment Voting

15/213 V. Larocca

Financial Intermediation and Deposit Contracts: A Strategic View

15/212 H. Gersbach and H. Haller

Formal and Real Power in General Equilibrium

15/211 L. Bretschger and J. C. Mollet

Prices vs. equity in international climate policy: A broad perspective 
15/210 M. Filippini and F. Heimsch

The regional impact of a $\mathrm{CO} 2$ tax on gasoline demand: a spatial econometric approach

15/209 H. Gersbach and K. Wickramage

Balanced Voting

15/208 A. Alberini and C. Towe

Information v. Energy Efficiency Incentives: Evidence from Residential Electricity Consumption in Maryland

14/207 A. Bommier

A Dual Approach to Ambiguity Aversion

14/206 H. Gersbach, U. Schetter and M. T. Schneider

Taxation, Innovation, and Entrepreneurship

14/205 A. Alberini and A. Bigano

How Effective Are Energy-Efficiency Incentive Programs? Evidence from Italian Homeowners

14/204 D. Harenberg and A. Ludwig

Social Security in an Analytically Tractable Overlapping Generations Model with Aggregate and Idiosyncratic Risk

14/203 A. Bommier, L. Bretschger and F. Le Grand

Existence of Equilibria in Exhaustible Resource Markets with Economies of Scale and Inventories

14/202 L. Bretschger and A. Vinogradova

Growth and Mitigation Policies with Uncertain Climate Damage

14/201 L. Bretschger and L. Zhang

Carbon policy in a high-growth economy: The case of China

14/200 N. Boogen, S. Datta and M. Filippini

Going beyond tradition: Estimating residential electricity demand using an appliance index and energy services

14/199 V. Britz and H. Gersbach

Experimentation in Democratic Mechanisms

14/198 M. Filippini and E. Tosetti

Stochastic Frontier Models for Long Panel Data Sets: Measurement of the Underlying Energy Efficiency for the OECD Countries

14/197 M. Filippini and W. Greene

Persistent and Transient Productive Inefficiency: A Maximum Simulated Likelihood Approach 